\title{
Questionnaire on switching from the tiotropium HandiHaler to the Respimat inhaler in patients with chronic obstructive pulmonary disease: changes in handling and preferences immediately and several years after the switch
}

This article was published in the following Dove Press journal: International Journal of COPD

6 January 2015

Number of times this article has been viewed

\author{
Soichiro Hanada' \\ Shota Wada' \\ Takeshi Ohno' \\ Hirochiyo Sawaguchi' \\ Masato Muraki' \\ Yuji Tohda ${ }^{2}$ \\ 'Department of Respiratory Medicine \\ and Allergology, Nara Hospital, Kinki \\ University Faculty of Medicine, Ikoma, \\ ${ }^{2}$ Department of Respiratory Medicine \\ and Allergology, Kinki University \\ Faculty of Medicine, Osakasayama, \\ Japan
}

Background: Tiotropium (Spiriva) is an inhaled muscarinic antagonist for patients with chronic obstructive pulmonary disease (COPD), and is available in two forms: the HandiHaler and the Respimat inhaler. The aim of this study was to investigate the handling of and preference for each device immediately after switching from the HandiHaler to the Respimat and 2-3 years after the switch.

Materials and methods: The study comprised two surveys. A questionnaire was first admin-

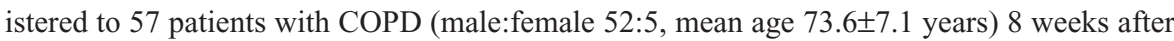
switching from the HandiHaler $(18 \mu \mathrm{g})$ to the Respimat $(5 \mu \mathrm{g})$. A second similar but simplified questionnaire was administered to 39 of these patients who continued to use the Respimat and were available for follow-up after more than 2 years. Pulmonary function was also measured during each period.

Results: In the first survey, $17.5 \%$ of patients preferred the HandiHaler, and $45.6 \%$ preferred the Respimat. There were no significant changes in pulmonary function or in the incidence of adverse events after the switch. In the second survey, performed 2-3 years later, the self-assessed handling of the Respimat had significantly improved, and the number of patients who preferred the Respimat had increased to $79.5 \%$.

Conclusion: The efficacy of the Respimat was similar to that of the HandiHaler. This was clear immediately after the switch, even in elderly patients with COPD who were long-term users of the HandiHaler. The preference for the Respimat increased with continued use.

Keywords: chronic obstructive pulmonary disease, tiotropium, HandiHaler, Respimat, questionnaire, pulmonary function

\section{Introduction}

Inhaled medications are the first choice for treating airway disease, as they enable direct delivery into the airway, are instantly effective, and require only small doses, which reduces the incidence of systemic side effects. ${ }^{1}$ Aside from the characteristics of the drug itself, the inhalation device also affects adherence, drug distribution, and drug deposition into the airway. ${ }^{1,2}$ Therefore, the therapeutic success of inhaled medications relies not only on the efficacy of the drug but also on the handling characteristics of and preference for a particular inhalation device.

Long-acting muscarinic antagonists are very important in the management of chronic obstructive pulmonary disease (COPD). ${ }^{3}$ Tiotropium $\left(\right.$ Spiriva $\left.^{\circledR}\right)$ is a once-daily
Correspondence: Masato Muraki Department of Respiratory Medicine and Allergology, Nara Hospital, Kinki University Faculty of Medicine, I248-I Otoda-cho, Ikoma, Nara 630-0298, Japan Tel +8I 743770880

Fax +81743770890

Email muraki@nara.med.kindai.ac.jp 
inhaled long-acting muscarinic antagonist used to treat COPD, and has a duration of action greater than 24 hours. ${ }^{4-6}$ Tiotropium exhibits pharmacokinetic selectivity for the $M_{3}$ and $M_{1}$ receptors. ${ }^{7}$ It was introduced in capsule form for inhalation using the HandiHaler ${ }^{\circledR}$, which is a single-dose dry-powder inhaler, and received marketing approval in Japan in 2004. In 2010, a new inhalation device for delivering tiotropium became available, the Respimat ${ }^{\circledR}$ Soft Mist ${ }^{\mathrm{TM}}$ Inhaler, which is a novel, propellant-free inhaler that delivers a fine-particle fraction of over $65 \%{ }^{8}$ The Respimat reportedly has high levels of satisfaction in COPD patients, due to its inhalation and handling characteristics. ${ }^{9}$

The administration of tiotropium via the Respimat has been reported to be potentially toxic, ${ }^{10-12}$ and further study comparing tiotropium delivery with the HandiHaler has been suggested. ${ }^{13}$ One recent mega-study, the TIOSPIR trial, did not report any difference in mortality or exacerbation rates between tiotropium delivered by the HandiHaler or the Respimat. ${ }^{14}$ Moreover, the Respimat (5 $\mu \mathrm{g}$ ) and the HandiHaler $(18 \mu \mathrm{g})$ reportedly exert a similar clinical effect. ${ }^{15,16}$ Chorão et al reported similar findings in a survey study comparing the correct use, ease of administration, and daily preference between patients using the Respimat or HandiHaler. ${ }^{17}$ However, little is known on the potential temporal changes in the handling of and preference for inhalation devices, although surveys evaluating the use of these devices have been conducted previously. ${ }^{9,17,18}$

In the present study, a questionnaire was administered to patients with COPD who switched to the Respimat after using the HandiHaler, and their level of satisfaction with each was investigated and compared. The clinical effect of switching to the Respimat on pulmonary function was also evaluated. A second, simpler questionnaire was administered to the patients who continued to use the Respimat for 2-3 years after the switch, and their satisfaction with the Respimat was examined. Finally, the relationship between any decline in pulmonary function and questionnaire responses was evaluated.

\section{Materials and methods}

This open-label clinical observational study was performed in two stages. In the first stage, a questionnaire on the use of each inhaler was administered 8 weeks after the patients switched from the HandiHaler to the Respimat. Changes in pulmonary function associated with the switch were also investigated. In the second stage, patients who continued to use the Respimat for 2-3 years after the initial switch were administered a similar but simplified questionnaire, and the annual change in pulmonary function was examined. The study protocol was approved by the institutional review board at Nara Hospital, Kinki University Faculty of Medicine, and informed consent was obtained from all patients. The study was performed in a real-world setting without randomization.

The first survey enrolled 57 patients with COPD examined at the Department of Respiratory Medicine and Allergology at Nara Hospital, Kinki University Faculty of Medicine, Ikoma, Japan between August 2010 and May 2011. COPD was diagnosed according to the GOLD (Global initiative for chronic Obstructive Lung Disease) 2006 criteria. ${ }^{19}$ The inclusion criteria were as follows: age over 40 years, smoking history of $>10$ pack-years, and stable disease without any exacerbations during the 3 months prior to the study. The exclusion criteria were as follows: inability to inhale on own; inability to perform spirometry; pregnancy; severe comorbidities affecting the quality of life, such as malignancy, cardiac failure, renal failure, or severe liver dysfunction; and contraindications to muscarinic antagonist medication. Due to a change in the prescription practices at our institution, COPD patients were consecutively switched from the HandiHaler (one cap $=18 \mu \mathrm{g}$, once daily in the morning) to the Respimat (two puffs $=5 \mu \mathrm{g}$, once daily in the morning). Pharmacists instructed patients on the use of the Respimat device using an illustrated pamphlet and manual demonstration, and observed the patients utilizing the device. The patients were administered a baseline questionnaire during a morning appointment after receiving a written summary describing the correct use of each inhalation device. Eight weeks after the switch, the first questionnaire for the two tiotropium inhalers was administered. Pulmonary function testing was conducted before and 8 weeks after the switch using a Chestac-33 (CHEST MI, Tokyo, Japan) 2-4 hours after the patients were administered their normal morning medications (tiotropium and all other morning medications). Pulmonary function was compared between 24 subjects who provided additional informed consent for this procedure.

The first questionnaire comprised seven questions, as follows: inhaler use (question one), perceived efficacy (question two), difficulties with administration (question three), adverse events (question four), overall satisfaction (question five), preference for Respimat versus HandiHaler (question six), and free comments (question seven).

The second survey was similar, but omitted several questions from the first questionnaire, and was administered to 
the 39 subjects who had continued to use the Respimat for 2-3 years after the switch and were available for follow-up. Because more than 2 years had passed since discontinuation of the HandiHaler inhaler, several items in the first questionnaire were deleted from the second questionnaire. The second survey evaluated changes in inhaler use and satisfaction 2-3 years after switching to the Respimat, and was conducted between May 2013 and November 2013. Associations between the survey responses and pulmonary function were evaluated in 37 subjects with a measurable decline in their annual forced expiratory volume in 1 second $\left(\mathrm{FEV}_{1}\right)$. Pulmonary function was measured in patients with stable disease, the values were plotted graphically, and the annual change in function was derived from the slope of the resulting equation.

\section{Statistical analysis}

Data are presented as means \pm standard deviation. Statistical differences were assessed using the Wilcoxon signedrank test. Survey responses were scored from one to five. Statistical analyses were performed using JMP version 10.0.2 statistical software (SAS Institute Japan, Tokyo, Japan), and $P<0.05$ was considered statistically significant.

\section{Results}

\section{First survey: HandiHaler versus Respimat}

Fifty-seven patients completed the first survey (Table 1). The population included $52(91.2 \%)$ men, and had a mean age of $73.6 \pm 7.1$ years. The mean maximum inspiratory flow was $44.1 \pm 8.8 \mathrm{~L} / \mathrm{min}$, as measured using an In-Check Oral Inspiratory Flow Meter (Matsuyoshi, Tokyo, Japan); an adaptor was used for the HandiHaler. The percentage of patients with moderate (GOLD II) and severe (GOLD III) airflow limitation was high. ${ }^{3}$ The survey results 8 weeks after switching to the Respimat are summarized in Figures 1-3. No concomitant medications were added during the 8-week period, and all patients completed the survey. There was no significant difference between the HandiHaler and Respimat in the self-reported usage, although the percentage of Respimat users rating their technique as "rather poor" or "poor" was higher than the percentage for HandiHaler users. There was no significant difference between the HandiHaler and Respimat in the incidence of shortness of breath (dyspnea), the use of breath-holding, or overall handling (Figure 1). However, the inhalation technique for the Respimat was significantly more difficult than the technique for the HandiHaler $(P=0.049)$. Significantly more respondents

Table I Patient characteristics

\begin{tabular}{|c|c|c|}
\hline & First survey $^{a}$ & Second survey \\
\hline$n$ & 57 & 39 \\
\hline Age (years) & $73.6 \pm 7.1(53-87)$ & $73.1 \pm 7.3$ \\
\hline Sex (male:female) & $52: 5$ & $37: 2$ \\
\hline Body mass index $\left(\mathrm{kg} / \mathrm{m}^{2}\right)$ & $21.0 \pm 2.6$ & $20.7 \pm 2.7$ \\
\hline \multicolumn{3}{|l|}{ Peak inspiratory flow (L/min) } \\
\hline Without adaptor & $175.8 \pm 67.8(50-327)$ & $176.5 \pm 6 \mid .2(60-327)$ \\
\hline With adaptor $(\mathrm{HH})$ & $44.1 \pm 8.8(30-65)$ & $43.8 \pm 7.9(30-65)$ \\
\hline VC (\%) & $96.3 \pm 21.4$ & $96.7 \pm 19.1$ \\
\hline FVC (\%) & $94.6 \pm 22.3$ & $95.6 \pm 20.6$ \\
\hline $\mathrm{FEV}_{1} / \mathrm{FVC}(\%)$ & $46.4 \pm 10.7$ & $44.4 \pm 10.0$ \\
\hline Predicted \% FEV (\%) & $64.0 \pm 24.4$ & $61.8 \pm 24.2$ \\
\hline \multicolumn{3}{|l|}{ Severity of airflow limitation (\%) } \\
\hline GOLD I: mild & 9.6 & 8.6 \\
\hline GOLD 2: moderate & 44.2 & 42.9 \\
\hline GOLD 3: severe & 36.5 & 37.1 \\
\hline GOLD 4: very severe & 9.6 & 11.4 \\
\hline Long-term oxygen therapy (\%) & $12(2 \mid .1)$ & $9(23.1)$ \\
\hline Asthma complications (\%) & $8(14.0)$ & $2(5.1)$ \\
\hline \multicolumn{3}{|l|}{ Duration of HandiHaler use } \\
\hline$<\mathrm{I}$ year & 8 & 4 \\
\hline$\geq$ I year & 49 & 35 \\
\hline Duration between the surveys & NA & $933 \pm 5$ I $(735-I, 072)$ \\
\hline
\end{tabular}

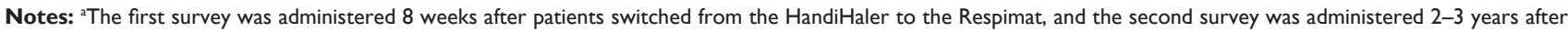
patients continued Respimat treatment. Data presented as the mean \pm standard deviation (range) unless otherwise indicated.

Abbreviations: $\mathrm{n}$, number of patients; $\mathrm{HH}$, HandiHaler; VC, vital capacity; FVC, forced vital capacity; FEV , forced expiratory volume in one second; NA, not applicable; GOLD, Global Initiative for Chronic Obstructive Lung Disease. 


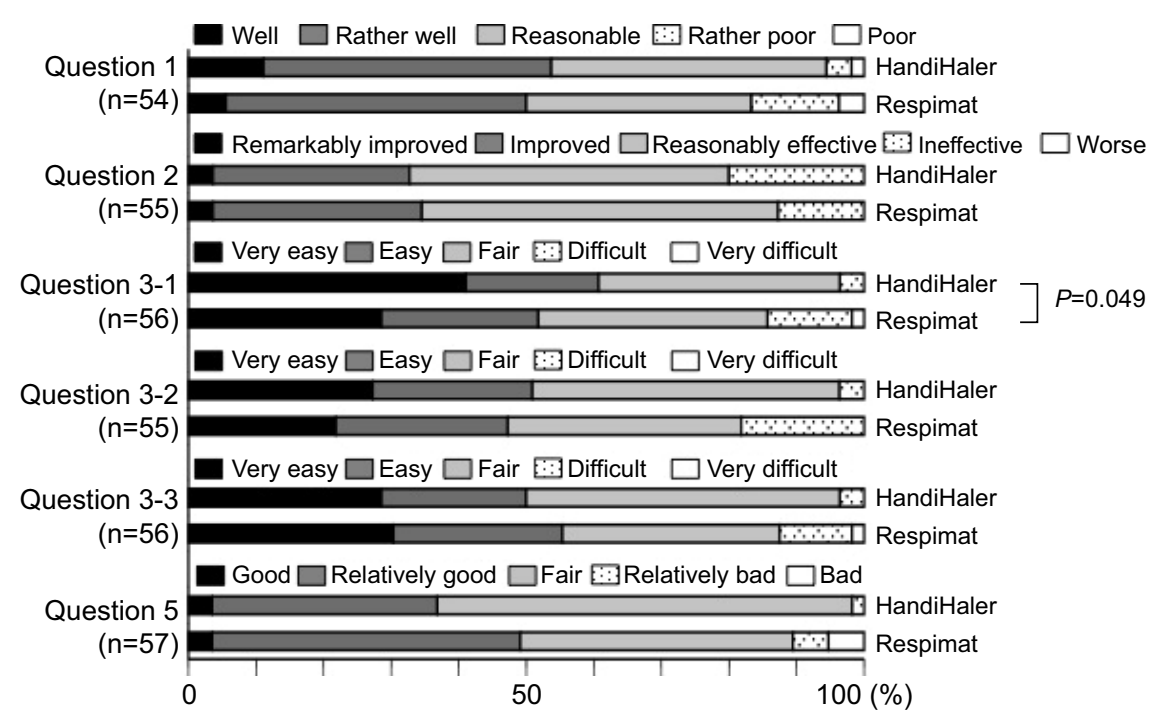

Figure I Initial questionnaire on usage, effectiveness, inhalation technique, and overall satisfaction 8 weeks after switching from the HandiHaler to the Respimat inhaler. Notes: Question I, Do you think that you can use Spiriva well? Question 2: What do you think about the effect of Spiriva on shortness of breath or dyspnea? Question 3: Please tell us about any difficulties you experienced when using each inhaler as follows: Q3-I, on inhalation technique; Q3-2, on breath-holding technique; Q3-3, on overall handling or usability. Question 5: Please tell us your overall satisfaction with Spiriva for each inhaler. The inhalation technique required for Respimat was significantly more difficult than that required for the HandiHaler ( $P=0.049$, question $3-1)$, but there was no significant difference in the usage (question I), perceived effect of the medication (question 2), breath-holding technique (question 3-2), or overall handling (question 3-3). Evaluations of the Respimat were classified as "good" or "bad" (question 5), but no significant difference was detected between the devices.

reported a milder aftertaste with the Respimat compared with the HandiHaler $(P=0.004)$, but no other significant adverse events were reported (Figure 2). No significant differences were detected in the overall satisfaction with the HandiHaler and Respimat, but the proportion of both good and bad responses was higher with the Respimat compared with the HandiHaler (Figure 1). A total of $45.6 \%$ of

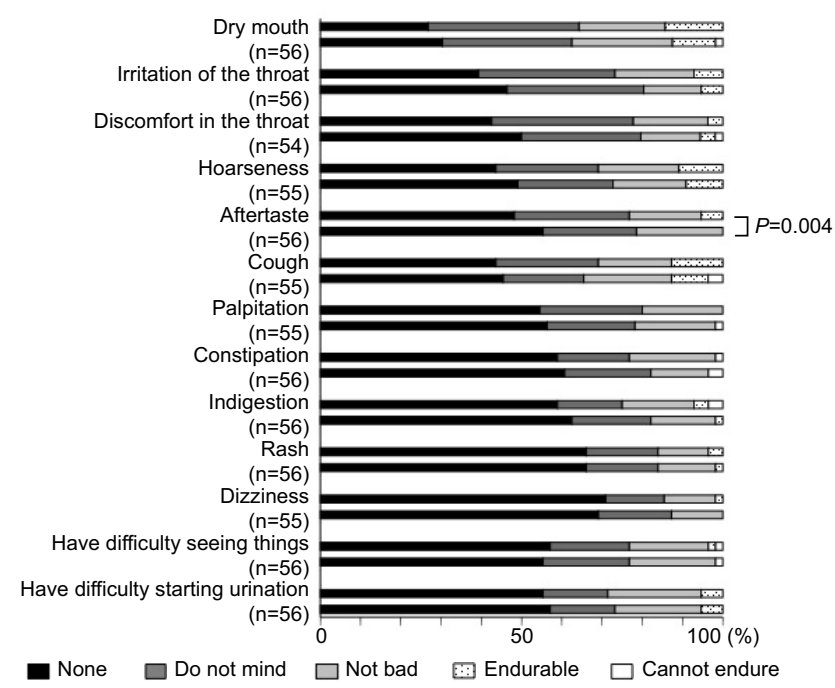

Figure 2 Questionnaire on adverse events 8 weeks after switching from the HandiHaler inhaler to the Respimat inhaler.

Notes: Respimat had a significantly milder aftertaste than the HandiHaler $(P=0.004)$, but there were no other significant differences in the incidence of adverse events (question 4: Please indicate whether you experienced any of the following symptoms after using each device). patients preferred the Respimat, while $17.5 \%$ preferred the HandiHaler (Figure 3).

\section{Changes in pulmonary function after switching from the HandiHaler to the Respimat}

Pulmonary function was evaluated before and 8 weeks after the switch to the Respimat in 24 subjects who completed the first questionnaire survey and completed the pulmonary function test on the day of the switch and again at the time of survey. The mean vital capacity significantly improved after the switch from the HandiHaler to the Respimat $(P=0.018)$;

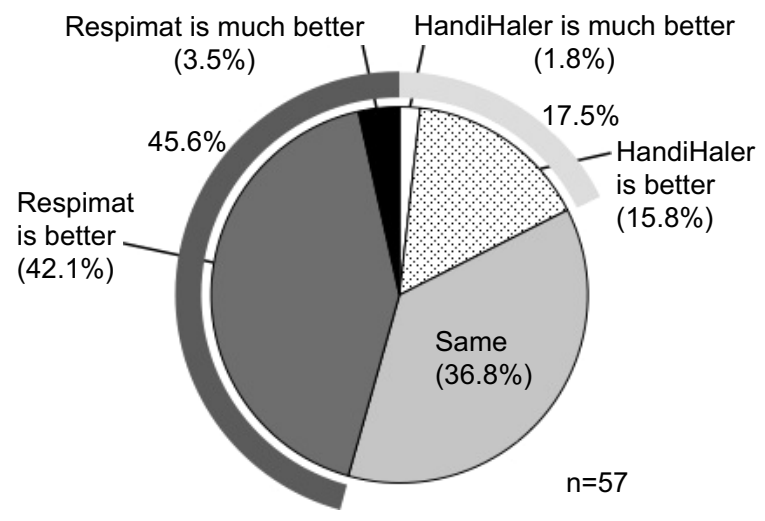

Figure 3 Comparison of patient preference for the HandiHaler and Respimat. Note: A total $45.6 \%$ of patients preferred the Respimat compared with $17.5 \%$ who preferred the HandiHaler (question 6: Which inhaler do you prefer?). 
no other significant differences in pulmonary function were detected (Table 2). Furthermore, when the rate of change $(\Delta)$ in pulmonary function before and after the switch was compared between patients who preferred the HandiHaler and those who preferred the Respimat, no significant difference was detected (data not shown).

\section{Second survey: HandiHaler versus Respimat 2-3 years after switching to the Respimat}

Thirty-nine of the 57 patients included in the first survey continued to use the Respimat and were available for follow-up. Eighteen patients were excluded for the following reasons: death ( $n=6$, two respiratory-related, two circulatory-related, and two of unknown etiology), switching to a different hospital ( $\mathrm{n}=5$, including one case of comorbid lung cancer); discontinuing the Respimat ( $\mathrm{n}=2$; one patient stopped after 3 months due to stomatitis, and the second at 14 months due to insufficient efficacy); and dropout for unknown causes $(n=5)$. The two patients who stopped Respimat therapy did not request further treatment with the HandiHaler, and the patient who complained of stomatitis had a history of stomatitis while using the HandiHaler. A total of 21 patients were assessed.

In the second survey, the number of patients responding that they were able to use the Respimat inhaler "well" or "rather well" increased significantly to $68.4 \%$ from $47.4 \%$ in the first survey ( $P=0.0008$, question one in Figure 4). The use of breath-holding (question 3-2 in Figure 4) and overall handling of the Respimat (question 3-3 in Figure 4) also significantly improved ( $P=0.0017$ and $P=0.031$, respectively). Overall satisfaction with the HandiHaler 2-3 years after it was discontinued significantly decreased $(P=0.0436$, question 5 in Figure 4). In contrast, the percentage of patients who reported "good" or "relatively good" satisfaction with the Respimat

Table 2 Pulmonary function before and after switching from the HandiHaler to the Respimat

\begin{tabular}{|c|c|c|c|}
\hline $\mathbf{N}=\mathbf{2 4}$ & $\begin{array}{l}\text { Before Respimat } \\
\text { treatment }\end{array}$ & $\begin{array}{l}\text { After Respimat } \\
\text { treatment }\end{array}$ & $P$-value \\
\hline VC (L) & $3.01 \pm 0.68$ & $3.10 \pm 0.60$ & 0.018 \\
\hline IC (L) & $2.01 \pm 0.60$ & $2.05 \pm 0.55$ & 0.218 \\
\hline FVC (L) & $2.99 \pm 0.69$ & $3.07 \pm 0.6 \mathrm{I}$ & 0.108 \\
\hline $\mathrm{FEV}_{1}(\mathrm{~L})$ & $1.39 \pm 0.55$ & $1.43 \pm 0.59$ & 0.195 \\
\hline$V_{50}$ & $0.57 \pm 0.4 \mathrm{I}$ & $0.6 \mathrm{I} \pm 0.44$ & 0.095 \\
\hline$V_{25}$ & $0.18 \pm 0.08$ & $0.19 \pm 0.09$ & 0.180 \\
\hline $\mathrm{V}_{50} / \mathrm{V}_{25}$ & $2.95 \pm 1.27$ & $2.93 \pm 1.10$ & 0.396 \\
\hline
\end{tabular}

Notes: Data presented as the mean \pm standard deviation. Significance at $P<0.05$. Abbreviations: VC, vital capacity; IC, inspiratory capacity; FVC, forced vital capacity; $\mathrm{FEV}_{1}$, forced expiratory volume in I second; $\mathrm{V}_{50}$, expiratory flow at $50 \%$ of vital capacity; $\mathrm{V}_{25}$, expiratory flow at $25 \%$ of vital capacity. increased from $46.2 \%$ to $74.4 \%$ over the same period, resulting in a significant improvement in overall satisfaction with the Respimat ( $P=0.0086$, question five in Figure 4). When the preference for HandiHaler versus Respimat was compared directly, the percentage of patients who preferred the Respimat significantly increased from $38.5 \%$ to $79.5 \%$ during the 2- to 3-year follow-up $(P<0.0001$, question six in Figure 5). In the free-comment section of the survey (question seven), 13 patients reported preferring the Respimat due to the "experience", and eight patients attributed their satisfaction to the "easy handling without the need to replace the inhalation capsule". Conversely, some dissatisfied patients reportedly disliked having to hold their breath after inhalation $(n=2)$. One patient reported failing to press the button and inhale at the appropriate moment on a few occasions, and another reported that having to inhale twice was troublesome.

\section{Associations between questionnaire responses and $\mathrm{FEV}$, decline}

Overall satisfaction with the Respimat was compared with the measured decline in $\mathrm{FEV}_{1}\left(\Delta \mathrm{FEV}_{1}\right)$ in the 39 patients who continued Respimat therapy and were available for follow-up. Eighteen patients who had had concomitant medications changed or added to their regimen were excluded from the analysis, and the data from 21 patients were analyzed.

Associations between $\triangle \mathrm{FEV}_{1}$ and changes in overall satisfaction with the Respimat were also measured (Figure 6). Aggravation was defined as a negative change between the first and second survey responses, such as a change from "good" to "relatively good" or from "fair" to "relatively bad". Improvement was defined as a positive change, such as from "bad" to "relatively bad" or from "relatively good" to "good". No change was defined as unchanged, such as from "bad" to "bad" or from "good" to "good". None of the differences between the three groups was statistically significant, but $\mathrm{FEV}_{1}$ was less likely to decline in patients who reported increased overall satisfaction with the Respimat.

\section{Discussion}

Several inhaled medications are used to treat COPD, and are delivered through various devices. The most commonly used devices are metered-dose inhalers, dry-powder inhalers, and nebulizers. All have limitations, particularly in elderly adults, as error rates rise with increasing age and severity of airflow obstruction..$^{20}$ According to several reports, tiotropium has superior clinical efficacy in patients with COPD and improves dyspnea, quality of life, ${ }^{21}$ and exercise tolerance; ${ }^{22}$ it also 


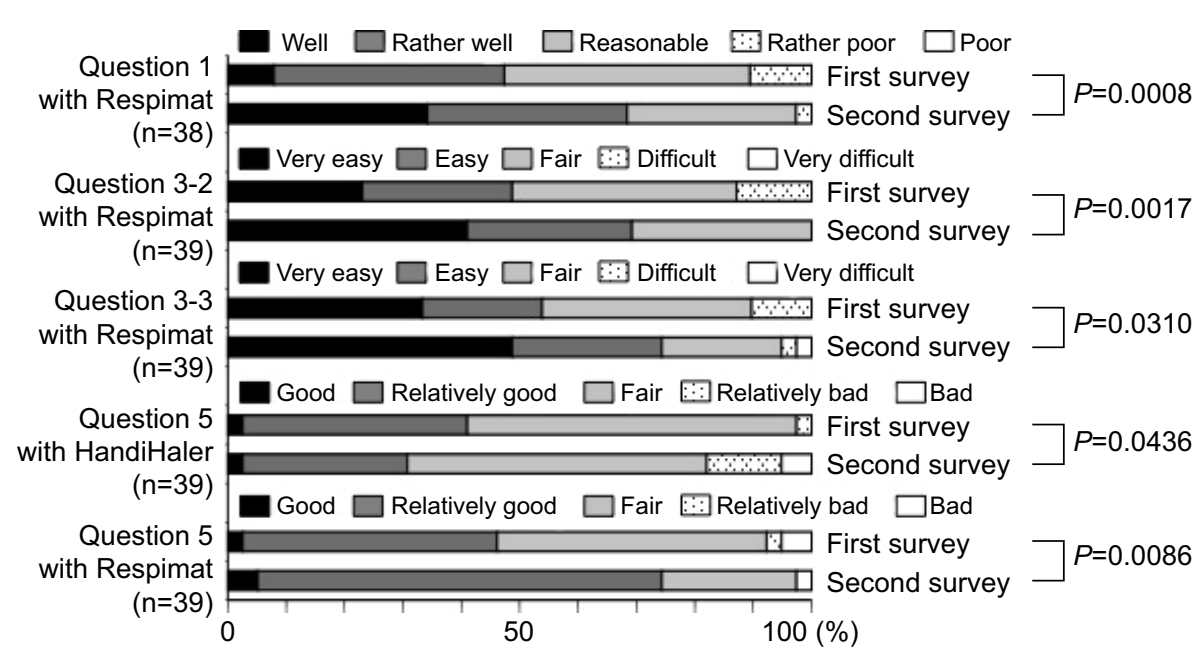

Figure 4 The second questionnaire administered 2-3 years after switching from the HandiHaler to the Respimat, and comparison of responses to those in the first survey. Notes: Question I: Do you think that you can use Spiriva well? Question 3: Please tell us about any difficulties you experienced when using each inhaler, as follows: Q3-2, on breath-holding technique; Q3-3, on overall handling or usability. Question 5: Please give us your overall satisfaction with Spiriva for each device. The usage (question I), perceived breath-hold technique (question 3-2), overall handling (question 3-3), and overall satisfaction (question 5) with Respimat were significantly improved compared to the results of the first survey $(P=0.0008, P=0.0017, P=0.031$, and $P=0.0086$, respectively). The overall satisfaction with the HandiHaler was significantly worse in the second survey $(P=0.0436$, question 5$)$.

prevents COPD exacerbations, ${ }^{23-25}$ may suppress disease progression, ${ }^{26-28}$ and decreases mortality. ${ }^{29,30}$

The HandiHaler is a dry-powder, breath-activated inhalation system developed for inhalation therapy in patients with COPD. The device acts to evacuate the powder from a pierced capsule. Compared with metered-dose inhalers, the HandiHaler is associated with fewer errors during long-term use. ${ }^{31}$ In an experimental study, the HandiHaler was shown to deliver particles effectively to the lungs of COPD patients, despite a wide range of airflow limitations. ${ }^{32}$ However, it is unclear how much of the drug is deposited in the airways or where the drug particles are distributed in patients with airway disease.

The Respimat requires the patient to rotate part of the device and press a spray button to release the drug as a fine mist over 1.5 seconds. ${ }^{33}$ The device generates a slow-moving aerosol with a high fraction of fine particles, resulting in

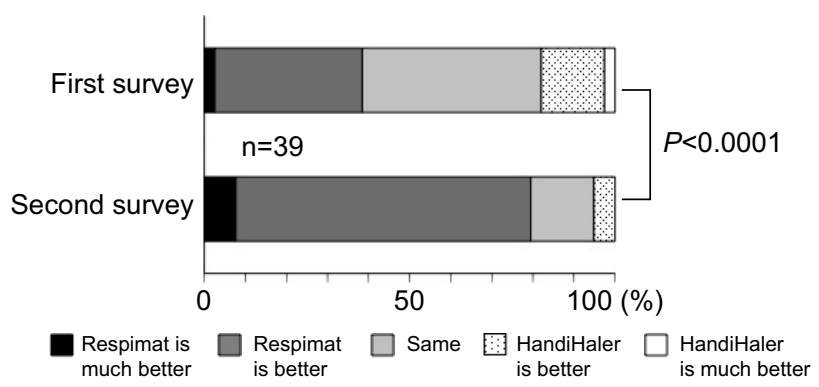

Figure $\mathbf{5}$ Changes in preference for Respimat between the first and second surveys. Note: The preference for Respimat significantly increased at the second survey (question 6: Which inhaler do you prefer? $[P<0.000 I]$ ). greater drug deposition into the lungs. ${ }^{9,34}$ Handling is simple, and does not require continued replacement of drug capsules. Like the HandiHaler, the Respimat promotes bronchodilation, prevents exacerbations, ${ }^{24}$ and improves physical function. ${ }^{35}$ In addition, the Respimat has a similar clinical efficacy and safety profile while using less than a third of the tiotropium dose required for the HandiHaler. ${ }^{14,15}$

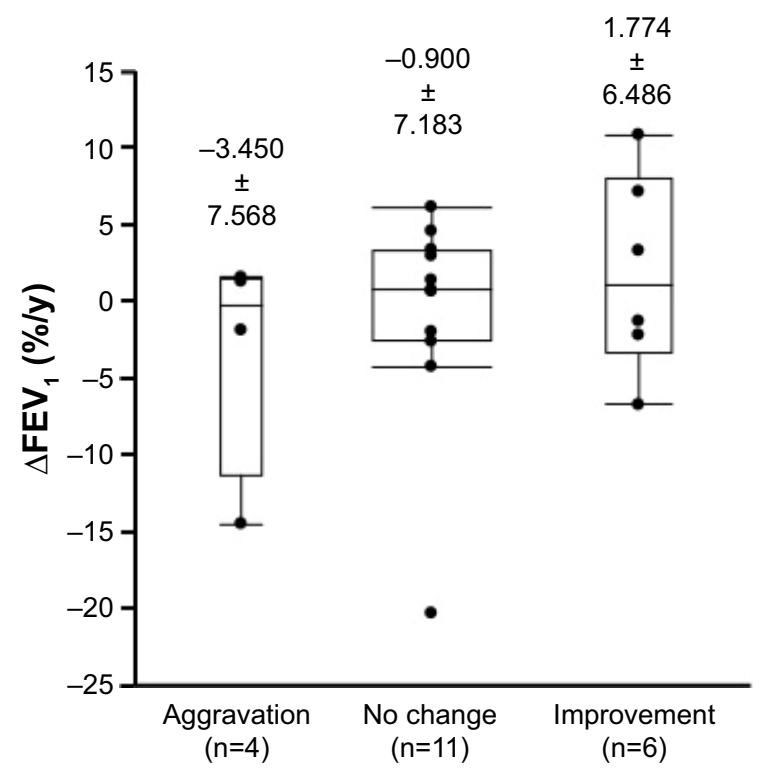

Figure 6 Annual decline in $\mathrm{FEV}_{\text {, }}$ in patients classified according to the change in overall satisfaction with each device.

Notes: A greater improvement in overall satisfaction was associated with a lower decline in $\mathrm{FEV}_{1}$, although the differences between the three groups were not significant. Data are presented as the mean \pm standard deviation.

Abbreviation: $\triangle \mathrm{FEV}_{\mathrm{l}}$, decline in forced expiratory volume in I second. 
In the first survey, which was administered 8 weeks after the patients had switched from the HandiHaler to the Respimat, the patients' self-reports of their inhalation technique and handling (especially the inhalation technique) were worse for the Respimat compared with their self-assessments for the HandiHaler, although the reported difference was not significant. This may have been because the majority of the patients were elderly and were long-term users of the HandiHaler, seven patients had used the HandiHaler for 1-2 years, 38 for more than 2 years, and four patients for more than 1 year, though the exact periods of use were unknown. Therefore, at the time of the survey, the patients had had less experience with the Respimat. However, their impression of the effect of the Respimat on shortness of breath (dyspnea) was similar to or better than their evaluations of the HandiHaler, though this difference was not significant; slightly more patients responded that Respimat was "effective" or "improved" their control of dyspnea. There was no significant difference between the HandiHaler and Respimat in the incidence of adverse events, except for a milder aftertaste with the latter. Collectively, these findings may explain the higher frequency of extremely good and bad responses for the Respimat after the switch from the HandiHaler. Despite the high number of elderly and long-term HandiHaler users, more patients preferred the Respimat in the final analysis. Asakura et al similarly reported that there were no major complications in patients switching from the HandiHaler to the Respimat, although they did observe coughing in patients just after inhalation. ${ }^{33}$ Several patients also reported a cough after inhalation in the present study, but none discontinued the Respimat despite the cough, and we did not observe any significant adverse effects following the switch.

In the present study, no significant changes in pulmonary function were observed 8 weeks after the switch to the Respimat, except in vital capacity. The equivalent effect of the HandiHaler (18 $\mu \mathrm{g} /$ day) and the Respimat (5 $\mu \mathrm{g} /$ day) on pulmonary function confirms previous findings. ${ }^{11,15,16,36}$ A recent large-scale study also confirmed the efficacy and safety of the Respimat. ${ }^{14}$ The mean plasma concentration of tiotropium was slightly lower with the Respimat $5 \mu \mathrm{g}$ compared with the HandiHaler $18 \mu \mathrm{g}$, yet the Respimat $5 \mu \mathrm{g}$ had comparable bronchodilator efficacy to the HandiHaler $18 \mu \mathrm{g}$ with lower systemic exposure. ${ }^{16}$

A variety of inhalation devices are currently available to COPD patients, and the choice of device is an important consideration, because it influences patient adherence to treatment, potentially affecting long-term outcomes. ${ }^{9}$ A second questionnaire was administered to assess changes in the handling of and preference for the Respimat in COPD patients who had continued to use the Respimat for more than 2 years. The handling and overall evaluation of the Respimat significantly improved over 2-3 years, while the evaluation of the HandiHaler worsened significantly. One reason for this finding may have been the improved experience reported by the users, which may have promoted a change in preference. In addition, continual use of the Respimat may have increased trust in the medication and confidence in its handling.

There are several limitations in the present study. Only a small number of patients were assessed; therefore, it is possible that there was no significant change in mean $\mathrm{FEV}_{1}$ decline over the 2- to 3-year period between patients reporting an improvement and those reporting an aggravation. Improved handling or preference may have contributed to the improvement or prevention of further decline in pulmonary function, which highlights the clinical importance of the preference for the Respimat.

This study was not a parallel randomized trial of two groups, but was instead an observational study in a clinical setting in a small number of patients. The switch to the Respimat was not done at the patients' request, which may have negatively influenced the overall preference for each inhaler. However, none of the patients, even those who initially preferred the HandiHaler, requested transition back to the HandiHaler, and all agreed to continue the Respimat, with the exception of two patients who discontinued Respimat treatment. In addition, the simple questionnaire used in the present study has not been validated. The survey was not designed to assess the total score of the responses as a whole, but instead only assessed each item individually.

Also notable, while the subjects were able to use the Respimat correctly at the first survey following detailed instruction, we did not confirm whether the patients used the HandiHaler correctly. The study was based on the selfperception of the patients, who responded to the questionnaire after reviewing instruction on handling procedures for the Respimat. As a result, the objectivity of the responses may be weak, as the inhaler technique could not be assessed for both devices, and there was no mechanism to account for incorrect use.

In some patients, the COPD medications were changed during the 2- to 3-year period of Respimat treatment, and the effects of concomitant medications for comorbidities were not assessed. Furthermore, patient adherence to each treatment could not be assessed using the present study design. The change in smoking status was not completely investigated, though none of the patients enrolled in the study 
of $\mathrm{FEV}_{1}$ decline, who were all ex-smokers, resumed smoking; therefore, the study may be statistically underpowered. Finally, over $90 \%$ of our cohort were men; therefore, the findings may be invalid in women, although the male-tofemale ratio of COPD in Japan is 16.4:5. ${ }^{37}$

\section{Conclusion}

Although the majority of patients in the present study were elderly and were long-term users of the HandiHaler, a preference for the Respimat over the HandiHaler was clear even at 8 weeks. No serious adverse events were encountered when switching from the HandiHaler to the Respimat. In addition, the preference for and handling of the Respimat improved with continual use of the device. The Respimat thus appears to be therapeutically indicated for many patients with COPD, and the improved handling and preference for the Respimat may lead to superior COPD management. However, the different responses obtained in the first and second surveys may also indicate that the change in inhaler was stressful for the COPD patients. Suitable selection of an appropriate inhalation device for primary therapy is thus extremely important.

\section{Acknowledgment}

This study was funded by the Department of Respiratory Medicine and Allergology, Nara Hospital, Kinki University Faculty of Medicine.

\section{Disclosure}

The authors report no conflicts of interest in this work.

\section{References}

1. Newman SP. Inhaler treatment options in COPD. Eur Respir Rev. 2005;14(96):102-108.

2. Mäkelä MJ, Backer V, Hedegaard M, Larsson K. Adherence to inhaled therapies, health outcomes and costs in patients with asthma and COPD. Respir Med. 2013;107(10):1481-1490.

3. Global initiative for chronic Obstructive Lung Disease (GOLD). Global Strategy for the Diagnosis, Management, and Prevention of Chronic Obstructive Pulmonary Disease. Bethesda (MD): GOLD; 2014.

4. van Noord JA, Bantje TA, Eland ME, Korducki L, Cornelissen PJ. A randomised controlled comparison of tiotropium and ipratropium in the treatment of chronic obstructive pulmonary disease. The Dutch Tiotropium Study Group. Thorax. 2000;55(4):289-294.

5. Vincken W, van Noord JA, Greefhorst AP, et al. Improved health outcomes in patients with COPD during 1 yr's treatment with tiotropium. Eur Respir J. 2002;19(2):209-216.

6. Casaburi R, Mahler DA, Jones PW, et al. A long-term evaluation of once-daily inhaled tiotropium in chronic obstructive pulmonary disease. Eur Respir J. 2002;19(2):217-224.

7. Disse B, Speck GA, Rominger KL, Witek TJ Jr, Hammer R. Tiotropium (Spiriva): mechanistical considerations and clinical profile in obstructive lung disease. Life Sci. 1999;64(6-7):457-464.

8. Zierenberg B. Optimizing the in vitro performance of Respimat. J Aerosol Med. 1999;12 Suppl 1:S19-S24.
9. Hodder R, Price D. Patient preferences for inhaler devices in chronic obstructive pulmonary disease: experience with Respimat Soft Mist inhaler. Int J Chron Obstruct Pulmon Dis. 2009;4:381-390.

10. Karner C, Chong J, Poole P. Tiotropium versus placebo for chronic obstructive pulmonary disease. Cochrane Database Syst Rev. 2012;7:CD009285.

11. Van Noord JA, Cornelissen PJ, Aumann JL, Platz J, Mueller A, Fogarty C. The efficacy of tiotropium administered via Respimat Soft Mist Inhaler or HandiHaler in COPD patients. Respir Med. 2009;103(1): 22-29.

12. Loke YK, Singh S. Risks associated with tiotropium in chronic obstructive airways disease: overview of the evidence to date. Ther Adv Drug Saf. 2012;3(3):123-131.

13. Singh S, Loke YK, Enright PL, Furberg CD. Mortality associated with tiotropium mist inhaler in patients with chronic obstructive pulmonary disease: systematic review and meta-analysis of randomised controlled trials. BMJ. 2011;342:d3215.

14. Wise RA, Anzueto A, Cotton D, et al. Tiotropium Respimat inhaler and the risk of death in COPD. $N$ Engl J Med. 2013;369(16):1491-1501.

15. Ichinose M, Fujimoto T, Fukuchi Y. Tiotropium $5 \mu \mathrm{g}$ via Respimat and $18 \mu \mathrm{g}$ via HandiHaler; efficacy and safety in Japanese COPD patients. Respir Med. 2010;104(2):228-236.

16. Hohlfeld JM, Sharma A, van Noord JA, et al. Pharmacokinetics and pharmacodynamics of tiotropium solution and tiotropium powder in chronic obstructive pulmonary disease. J Clin Pharmacol. 2014;54(4): 405-414.

17. Chorão P, Pereira AM, Fonseca JA. Inhaler devices in asthma and COPD - an assessment of inhaler technique and patient preferences. Respir Med. 2014;108(7):968-975.

18. Barrons R, Pegram A, Borries A. Inhaler device selection: special considerations in elderly patients with chronic obstructive pulmonary disease. Am J Health Syst Pharm. 2011;68(13):1221-1232.

19. Global initiative for chronic Obstructive Lung Disease (GOLD). Global Strategy for the Diagnosis, Management, and Prevention of Chronic Obstructive Pulmonary Disease. Bethesda (MD): GOLD; 2006.

20. Taffet GE, Donohue JF, Altman PR. Considerations for managing chronic obstructive pulmonary disease in the elderly. Clin Interv Aging. 2014;9:23-30

21. Ambrosino N, Foglio K, Balzano G, Paggiaro PL, Lessi P, Kesten S. Tiotropium and exercise training in COPD patients: effects on dyspnea and exercise tolerance. Int J Chron Obstruct Pulmon Dis. 2008;3(4): 771-780.

22. Maltais F, Hamilton A, Marciniuk D, et al. Improvements in symptomlimited exercise performance over $8 \mathrm{~h}$ with once-daily tiotropium in patients with COPD. Chest. 2005;128(3):1168-1178.

23. Vogelmeier C, Hederer B, Glaab T, et al. Tiotropium versus salmeterol for the prevention of exacerbations of COPD. $N$ Engl J Med. 2011; 364(12):1093-1103.

24. Bateman ED, Tashkin D, Siafakas N, et al. A one-year trial of tiotropium Respimat plus usual therapy in COPD patients. Respir Med. 2010; 104(10):1460-1472.

25. Tashkin DP, Celli B, Senn S, et al. A 4-year trial of tiotropium in chronic obstructive pulmonary disease. $N$ Engl J Med. 2008;359(15): $1543-1554$.

26. Decramer M, Celli B, Kesten S, Lystig T, Mehra S, Tashkin DP. Effect of tiotropium on outcomes in patients with moderate chronic obstructive pulmonary disease (UPLIFT): a prespecified subgroup analysis of a randomised controlled trial. Lancet. 2009;374(9696):1171-1178.

27. Troosters T, Celli B, Lystig T, et al. Tiotropium as a first maintenance drug in COPD: secondary analysis of the UPLIFT trial. Eur Respir J. 2010;36(1):65-73.

28. Morice AH, Celli B, Kesten S, Lystig T, Tashkin D, Decramer M. COPD in young patients: a pre-specified analysis of the four-year trial of tiotropium (UPLIFT). Respir Med. 2010;104(11):1659-1667.

29. Celli B, Decramer M, Kesten S, Liu D, Mehra S, Tashkin DP. Mortality in the 4-year trial of tiotropium (UPLIFT) in patients with chronic obstructive pulmonary disease. Am J Respir Crit Care Med. 2009; 180(10):948-955. 
30. Tashkin DP, Celli BR, Decramer M, Lystig T, Liu D, Kesten S. Efficacy of tiotropium in COPD patients with $\mathrm{FEV}_{1} \geq 60 \%$ participating in the UPLIFT trial. COPD. 2012;9(3):289-296.

31. Dahl R, Backer V, Ollgaard B, Gerken F, Kesten S. Assessment of patient performance of the HandiHaler compared with the metered dose inhaler four weeks after instruction. Respir Med. 2003;97(10):1126-1133.

32. Chodosh S, Flanders JS, Kesten S, Serby CW, Hochrainer D, Witek TJ Jr. Effective delivery of particles with the HandiHaler dry powder inhalation system over a range of chronic obstructive pulmonary disease severity. J Aerosol Med. 2001;14(3):309-315.

33. Asakura Y, Nishimura N, Maezawa K, Terajima T, Kizu J, Chohnabayashi N. Effect of switching tiotropium HandiHaler to Respimat Soft Mist Inhaler in patients with COPD: the difference of adverse events and usability between inhaler devices. J Aerosol Med Pulm Drug Deliv. 2013;26(1):41-45.
34. Pitcairn G, Reader S, Pavia D, Newman S. Deposition of corticosteroid aerosol in the human lung by Respimat Soft Mist inhaler compared to deposition by metered dose inhaler or by Turbuhaler dry powder inhaler. $J$ Aerosol Med. 2005;18(3):264-272.

35. Rau-Berger H, Mitfessel H, Glaab T. Tiotropium Respimat improves physical functioning in chronic obstructive pulmonary disease. Int $J$ Chron Obstruct Pulmon Dis. 2010;5:367-373.

36. Caillaud D, Le Merre C, Martinat Y, Aguilaniu B, Pavia D. A doseranging study of tiotropium delivered via Respimat Soft Mist Inhaler or HandiHaler in COPD patients. Int J Chron Obstruct Pulmon Dis. 2007;2(4):559-565.

37. Fukuchi Y, Nishimura M, Ichinose M, et al. COPD in Japan: the Nippon COPD Epidemiology study. Respirology. 2004;9(4):458-465.

International Journal of COPD

\section{Publish your work in this journal}

The International Journal of COPD is an international, peer-reviewed journal of therapeutics and pharmacology focusing on concise rapid reporting of clinical studies and reviews in COPD. Special focus is given to the pathophysiological processes underlying the disease, intervention programs, patient focused education, and self management protocols.

\section{Dovepress}

This journal is indexed on PubMed Central, MedLine and CAS. The manuscript management system is completely online and includes a very quick and fair peer-review system, which is all easy to use. Visit http://www.dovepress.com/testimonials.php to read real quotes from published authors.

Submit your manuscript here: http://www.dovepress.com/international-journal-of-chronic-obstructive-pulmonary-disease-journal 